\title{
Review on Seismic Behaviour of Diagrid Structure with Conventional Structure
}

\author{
Saurabh Babhulkar ${ }^{1}$, Dr. Kuldeep Dabhekar ${ }^{2}$, Prof. S.S. Sanghai ${ }^{3}$, Isha P Khedikar ${ }^{4}$, Suresh Bhomle ${ }^{5}$ \\ ${ }^{1} \mathrm{M}$-Tech. Student, Structural Engineering, G H Raisoni College of Engineering, Nagpur, India \\ 2,3.4Assistant Professor Civil Engineering Department, G H Raisoni College of Engineering Nagpur, India \\ ${ }^{5}$ Architect and Structural consultant, SB Arch and Associates, Nagpur, India
}

\section{Article Info}

Volume 8 Issue 2

Page Number: 386-391

Publication Issue :

March-April-2021

\section{Article History}

Accepted : 20 April 2021

Published : 26 April 2021

\section{ABSTRACT}

The major forces that acts on any structure and which can be the cause of major disasters are earthquake and wind. Many researches all over the globe found that tall structures are more vulnerable to disasters as compared to smaller structures And are the major sources of social, environmental degradation after disaster. To minimize the effect of these major forces mentioned above we need to develop such techniques to make structures more resistant thereby minimizing the damage to the society and minimize environmental degradation. For any structure which is going to be constructed strength should be given outmost importance. Advances in development innovation, materials, underlying frameworks and insightful techniques for investigation and configuration worked with the development of tall structures. Underlying model of tall structures is represented by sidelong loads because of wind or quake. Parallel burden opposition of design is given by inside underlying framework or outside primary framework. Generally shear divider center, supported casing and their mix with outlines are inside framework, where parallel burden is opposed by midway found components. While outlined cylinder, supported cylinder underlying framework oppose parallel burdens by components gave on outskirts of design. It is vital that the chose underlying framework is to such an extent that the primary components are used adequately while fulfilling plan prerequisites. As of late diagrid underlying framework is embraced in tall structures because of its primary productivity and adaptability in building arranging. Contrasted with firmly dispersed vertical segments in outlined cylinder, diagrid structure comprises of slanted sections on the outside surface of building. Because of slanted segments sidelong loads are opposed by pivotal activity of the corner to corner contrasted with twisting of vertical segments in outlined cylinder structure. Diagrid structures for the most part don't need center since horizontal shear can be conveyed by the diagonals on the outskirts of building.

Keywords : Diagrid Structural System, High rise buildings, Structural design, Staad pro 


\section{INTRODUCTION}

The fast developments of metropolitan populace and subsequent tension on restricted space have extensively impacted the private advancement of city. The significant expense of land, the craving to stay away from a ceaseless never-ending suburbia, and the need to save significant horticultural creation have all added to drive private structures upward. As the tallness of building increment, the horizontal burden opposing framework turns out to be a higher priority than the primary framework that opposes the gravitational burdens. The horizontal burden opposing frameworks that are broadly utilized are: unbending edge, shear divider, divider outline, propped tube framework, outrigger framework and cylindrical framework. As of late, the diagrid Diagonal Grid - primary framework is broadly utilized for tall steel structures because of its underlying proficiency and tasteful potential given by the interesting mathematical design of the framework Diagrid structures are a specific type of room outlines utilizing the overall type of cylindrical frameworks.

The perimeter diagonal elements are utilized to keep the structure stable without the presence of any columns in the outer surfaces. On the contrary to the braced frames, in which the diagonal elements are designed to withstand the lateral loads, in case of diagrid systems the triangular modules provide the resistance under both gravity and lateral loads In such systems, the lateral loads are transferred through the diagonals placed in the perimeter of the structure, and therefore, a concrete core with considerable shear stiffness will not be required. The predominant hub execution in the diagonals, can assume a significant part in limiting the shear and flexural distortions of the framework. Subsequently, contrasted with traditional second opposing casing frameworks, utilizing diagrid components can extensively diminish the steel utilization.

\section{OBJECTIVE}

Safety and minimum damage level of a structure could be the prime requirement of high rise buildings. The meet these requirement, the structure should have adequate lateral strength \& sufficient ductility. In this thesis I choose two 20 storey buildings, one for diagrid and other for conventional buildings, in and analysis value are compared in terms of Shear, Displacement, Drift and also the economical aspect is compared.

The work is to be carried out by comducating-

- Modelling of both the building frames.

- To analyse diagrid and conventional structural systems using staad pro software.

- To compare the performance of the building with diagrid strucral system and convetional farame system.

- To obtain the response in terms of parameters such a storey displacement, storey drift, storey shear.

- To study the concept of diagrid structural system.

\section{LITERATURE REVIEW}

[1] In 2015 Anju Krishna has done the near logical investigation of 36 story working of six model. In model $75 \%$, half and $25 \%$ is ordinary arrangement of complete tallness individually. Three model of diagird with supported point $74.5^{\circ}$ and three of cylindrical construction. Direct static examination is finished with assistance of Etabs programming and analyzes bring about term of story uprooting, bury story float. It is presumed that diagrid structure having vertical mathematical abnormality shows less top dislodging and bury story removal when contrasted with 
rounded vertical mathematical inconsistency. Diagrid framework additionally gives greater adaptability to inside arranging.

[2] khalid Sadhan broke down the tall structure applied breeze load with fluctuated diagrid point to control sidelong float in elevated structure exposed to wind load. Diagrid point is changed to five diverse point setups has considered for various tallness 24, 48 and 72 story steel building. Distinctive cross area diagrid part with various thickness grade 50 steel pipes is utilized. Limited component investigation is done in ETABS and results are contrasting in boundary horizontal removal and story float. It presume that diagrid point straightforwardly impact conduct of elevated structure under parallel burden and ideal diagrid point is little than $56^{\circ}$ for 24 story model and between $56^{\circ}$ to $72^{\circ}$ for 48 story model $\& 72^{\circ}$ for 72 story model.

[3, 4] Ravish Khan \& Sangeeta Shinde Studied two model diagrid structures with symmetric and asymmetric plan geometry. The area of building is in Aurangabad. Bar and daigrid are steel property section are solid property. Straight static investigation is done on Staad.pro programming. Result is investigation in term of story float, story shear and story drift.. Response of building is more efficient when subjected to wind load in symmetry of plan. Symmetric model comes out more efficient than the asymmetry in term of storey drift and storey displacement.

[5] Snehal S. Mali studied seismic response of diagrid building with conventional frame structure at seismic zone iv and soil type is hard. Model is of same parameter with diagrid and conventional frame. Position of diagrid in opposite face, three countenances, and all appearances in model are taken. Comparable static investigation, Response range examination and wind investigation is finished utilizing ETABS programming. Result is addressing in term of dislodging. It is reason that at identical static investigation, reaction range examination of diagrid structure sidelong dislodging fundamentally less $45.48 \%$ and $41.71 \%, 45.92 \%, 42.17 \%$ in $\mathrm{X}, \mathrm{Y}$ bearing individually when contrasted with ordinary construction. At wind investigation horizontal dislodging fundamentally diagrid structure contrasted with regular construction is less $45.34 \%$ in $\mathrm{X}$ and $41.59 \%$ in $Y$ heading.

[6] Chetan S. Pattar work the analysis 16 storey of diagrid structure with regular plan, C-type and L-type plan irregularity at zone V. All the structure has same area $324 \mathrm{~m} 2$. Response spectrum method used for dynamic analysis of structure and compared plan irregular structure with regular structure. Shear, top storey shear, top storey displacement, time period storey drift and quantity of material consumed by these term building are compared. It is concluding that consider base shear, top storey displacement, storey drift L-type diagrid structure is best and C-type structure consume least quantity of material.

[7] Rajesh kumar studied the comparative high rise building between the diagrid structure system and braced frame system. Six model are made in three set each set having one diagrid structure tye and one braced tube type. Diagonal member is kept same but density has changed in set. G+48, G+32 and G+20 is number of storey in different three set situated in Chandigarh zone VI. Models are dynamic analyzed on ETABS and STAADPro software. Displacement, storey drift and base shear are used to compare the models. It is concluding that brace frame result much better for luxury building because it increase comfort condition in building. All building models with in permissible limit criteria. Braced frame increases cost of building.

[8] In 2003 Rafael Sabelli studied on Seismic Demands on Steel Braced Frame Buildings with Buckling Restrained braces. This paper highlighted on the research being conducted in identifying ground motion and structural aspect, that control the feedback of concentrically braced frames, also identified the improved design procedures and code provisions. In this study the author was keened on the seismic response of three and six story concentrically 
braced frames utilizing bucklingrestrained braces. The examined results of the nonlinear dynamic analyses for specific cases as well as statistically for several suites of ground motions to characterize the effect on key response parameters of various structural configurations and proportions

[9] In 2007 Moon K.S. examine the influence of the diagonal angle on a behavior of diagrid type structure. It was found that, for 60-storey diagrid structures having an aspect ratio of about 7 , the optimal range of diagrid angle is from about $65^{\circ}$ to $75^{\circ}$ for 42 -storey building having an aspect ratio of about 5 , the range is lowered by around $10^{\circ}$ beacause the importance of bending to the total lateral displacement is reduce as the building height decreases.

[10] Ali M.M. Reviewed the evolution of tall building structural system and the technological driving force behind tall building development. A new classification for primary structural system as interior structures and exterior structures were presented. While most representative structural system for tall building were discussed, the main emphasis was on diagrid structures and outrigger system.

[11] Soo K.J Performed analysis on different structural systems to select the most efficient among them and to maximize the uniqueness of external appearance for a building to be located in Asam. During the concept design, three structural systems, outrigger with belt truss system, diagrid system and super column with super braced system were proposed. From the analysis results diagrid system was recommended for architectural planning, structural efficiency and stability. Diagrid system was concluded as the best system among them because the diagrid forms an exterior tube with much higher torsional rigidity than other systems.

[12] In 2015, Gupta played out the unique investigation of a 16-story diagrid and contemplated the heap circulation in this framework. A similar report between a diagrid structure and a comparing regular outlined design was additionally introduced to exhibit the upside of utilizing diagrid framework in tall building structures. It was seen that the diagrid systems contradict load by center action as no tremendous proportion of shear or second was seen under gravity similarly as equal stacking. The diagrid structures gave much better results against shake and wind load than a normal second contradicting packaging.

[13] In 2014, G. M. Montuori studied the geometrical patterns provided for the diagrid structures. For this purpose, diagrid structures of regular patterns were compared to different geometrical configurations, which were obtained by changing the angle of diagonals (variable-angle i.e. VA) and the number of diagonals (variable-density i.e. VD) along the height of the building. Eight kinds of the geometrical patterns were developed for the systematic and comprehensive study. The diagrid patterns generated for the buiding model were analyzed using FEM numerical models, by means of SAP2000 computer code. The diagrid patterns were designed for a 90 storey building model. The resulting diagrid structure was analyzed under gravity [10] [11] and wind [12] loads and various performance parameters were evaluated on the basis of analyses results.

[14] In 2014, G. M. Montuori investigated secondary bracing systems for diagrid structures in tall buildings. A framework was defined for assessing the structural issues in the design of tall buildings. For establishing the need of a specific secondary bracing system a methodology was presented. Design criteria for SBS was adopted and applied to some of the building models. A 90 storey building model was considered for the study. A properly designed secondary bracing system (SBS) was added to the diagrid building model because local deformation within the module height requires this which allows the transfer of horizontal forces to the diagrid nodes through the load path. It involves the axial stiffness of the SBS members instead of the flexural stiffness of the diagrid diagonal elements. Secondary bracing system also stabilizes the columns of gravity load resisting system (i.e. core columns) at the intermediate levels between two 
panel points. SBS consists of four concentric braced frames along the two orthogonal building direction for each diagrid building designed.

$[15,16]$ In 2013, K. Jani \& P. V. Patel analyzed and designed diagrid structural system for high rise steel buildings. A 36 storey diagrid steel building was adopted for the study. Also, 50, 60, 70 and 80 storey diagrid steel structures are analyzed and designed for the investigation. ETABS software was used for modelling and analyses of the structure. All the members of the structure were designed using IS 800:2007 [9]. All the load combinations were considered during design and analyses of the model. Structural design of the building was governed by lateral loads due to wind [12] or earthquake [7]. Lateral load acting over the structure was resisted by interior and structural system. Interior structural system consists of usually shear wall core, braced frame and their combination with frames where lateral load was resisted by centrally located elements while exterior structural system consists of framed tube and braced frame where lateral load was resisted by elements provided on the periphery of the structure.

[17] In 2011, K. S. Moon studied the structural performance of the diagrid systems in complex shaped tall buildings. The complex shaped tall building models considered for the study was twisted tower, tilted towers and freeform towers. The complex shaped tall building models were designed with diagrid systems, and their structural performance and efficiency potential was studied. For the study of impacts for variation of geometric configurations of complex shaped tall buildings. Parametric structural models were used for the study of rate of twisting and angle of tilting. On the basis of results obtained, design considerations are studied for using the diagrid system efficiently in complex shaped tall buildings.

\section{CONCLUSION}

The comparison of lateral load resisting systems is done by the researchers in the above studies. Some researchers have compared the top storey displacement of conventional system with Diagrid system and found that diagrid system is superior in performance to Conventional system. Some researchers have compared the storey drift and storey shear of the diagrid, The diagrid structure has been used prevalently for today's tall buildings worldwide. The unique compositional characteristic of the structure provides great structural efficiency for tall buildings and aesthetic potential in any existing orthogonal urban context. The structural efficiency of diagrids for tall buildings can be maximized by configuring them to have optimum grid geometries. Though the construction of a diagrid structure is challenging due to its complicated nodes, its constructability can be enhanced by appropriate prefabrication methods

\section{REFERENCES}

[1]. Anju Krishna and Arathi S, "Analytical Study of Vertical Geometric Irregular Diagrid Structure and Comparison with Tubular Structure,"International Journal of Science and Research, Vol. 5, Issue 7, pp.1355-1361, 2016

[2]. Khalid K. Shadhan, "OPTIMAL DIAGRID ANGLE TO MINIMIZE DRIFT IN HIGH-RISE STEEL BUILDINGSSUBJECTED TO WIND LOADS," International Journal of Civil Engineering and Technology, Vol. 6, Issue 11, pp. 01-10, 2015

[3]. Ravish Khan and Sangeeta Khan, "Analysis of Diagrids Using Symmetric and Asymmetric Plan Geometry," International Journal of Recent Advances in Engineering \& Technology, Vol. 4, Issue 3, pp. 9-13, 2016

[4]. Snehal S. Mali , D. M. Joshi and Roshni John, "Response of High Rise Building with Different Diagrid Structural System," International Journal of 
Science Technology \& Engineering, Vol. 4, Issue 5, pp. 144-150, 2107

[5]. Chetan S.Pattar and Prof. Smt. Varsha Gokak, "ANALYSIS OF DIAGRID STRUCTURES WITH PLAN IRREGULARITY," International Research Journal of Engineering and Technology, Vol. 05, Issue 08, pp. 435-438, 2018

[6]. Irfan Saleem and Dr. Sunil Kumar Tengli, "Parametric Study on Asymmetric Diagrid Structures," International Journal of Applied Engineering Research, Vol. 13, pp. 61- 66, 2018

[7]. rupti A. Kinjawadekar and Trupti A. Kinjawadekar, "COMPARATIVE STUDY OF SEISMIC CHARACTERISTICS OF DIAGRID STRUCTURAL SYSTEMS IN HIGH RISE CONSTRUCTION," International Journal of Civil Engineering and Technology, Vol. 9, Issue 6, pp.315-323, 2018

[8]. Swaral R. Naik, Dr. Satish N. Desai and Malhar P. Naik, "EARTHQUAKE RESPONSES OF DIAGRID BUILDINGS ANDCONVENTIONAL MOMENT FRAME BUILDINGS HAVINGDIFFERENT H/B RATIO CONSIDERING SEISMIC NON-LINEAR TIME HISTORY ANALYSIS," International Journal of Civil Engineering and Technology, Vol. 9, Issue 13, pp. 1532-1539,2018

[9]. Akshat and Gurpreet Singh, "DYNAMIC ANALYSIS OF DIAGRID STRUCTURAL SYSTEM IN HIGH RISE STEEL BUILDINGS," International Journal of Civil Engineering and Technology, Vol. 9, Issue 8, pp.71-79, 2018

[10]. Trupti A. Kinjawadekar and Amit C. Kinjawadekar, "COMPARATIVE STUDY OF SEISMIC CHARACTERISTICS OF DIAGRID STRUCTURAL SYSTEMS IN HIGH RISE CONSTRUCTION," International Journal of Civil Engineering and Technology, Vol. 9, Issue 6, pp. 315- 323, 2019

[11]. K. Jani, P. V. Patel, "Analysis and Design of Diagrid Structural System for High Rise Steel Buildings", Procedia Engineering, 51 (2013) 92-100.

[12]. K. Kamath, S. Hirannaiah, J. C. K. B. Noronha, “An analytical study on performance of a diagrid structure using non-linear static pushover analysis", Perspectives in Science, (2016) 8, 90-92.15K. S. Moon, "Diagrid Structures for Complex-Shaped Tall Buildings", Procedia Engineering, 14 (2011) 13431350 .
[13]. R. D. Deshpande, S. M. Patil, S. Ratan, “Analysis and comparison of diagrid and conventional structural system", International Research Journal of Engineering and Technology (IRJET), June 2015, Vol. 2, Issue 3, PP 2295-2300.

[14]. T. H. Kim, H. U. Lee, Y. C. Kim, "Development of a building structural system using an IsoTruss ${ }^{\circledR}$ grid”, Procedia Engineering, 171 (2017) 1077-1084.

[15]. Asadi E, Adeli H. Nonlinear behavior and design of mid-to-high rise diagrid structures in seismic regions. Eng J Am In st Steel Constr2018;55.

[16]. Chopra, A. K. et al., Dynamics of structures, volume 3. Prentice Hall New Jersey, 1995.

[17]. B K Raghu Prasad, Kavya A J "Comparative performance of octagrid and hexagrid lateral load resisting systems for tall building structure", International Journal of Engineering Research and Applications, 2014.

[18]. Nishith B. Panchal, Vinubhai R. Patel, "Diagrid structural system: strategies to reduce lateral forces on high-rise buildings", International Journal Of Research In Engineering And Technology, 2014

[19]. Kiran Kamath and Nawaz Ahamed, "Effect of aspect ratio on performance of diagrid structure circular in plan”, 2015.

[20]. Khushbu D. Jani, Paresh V. Patel, "Design of diagrid structural system for high rise steel buildings as per indian standards," ASCE Structures Congress, 2013.

\section{Cite this article as :}

Saurabh Babhulkar, Dr. Kuldeep Dabhekar, Prof. S. S. Sanghai, Isha P Khedikar, Suresh Bhomle, "Review on Seismic Behaviour of Diagrid Structure with Conventional Structure", International Journal of Scientific Research in Science, Engineering and Technology (IJSRSET), Online ISSN : 2394-4099, Print ISSN : 2395-1990, Volume 8 Issue 2, pp. 386-391, March-April 2021. Available at doi $\quad$ : https://doi.org/10.32628/IJSRSET218289 Journal URL : https://ijsrset.com/IJSRSET218289 